\title{
Glomerular Injury in Uninephrectomized Spontaneously Hypertensive Rats. A Consequence of Glomerular Capillary Hypertension
}

\author{
Lance D. Dworkin and Helen D. Feiner \\ With the technical assistance of Joseph Randazzo \\ Departments of Medicine and Pathology, New York University Medical Center, New York 10016
}

\begin{abstract}
Micropuncture and/or morphologic studies were performed in intact Wistar-Kyoto rats (WKY) (group 0), intact spontaneously hypertensive rats (SHR) (groups 1 and 5), uninephrectomized (UNX) WKY (groups 2 and 6), and UNX SHR (groups 3 and 4,7 and 8). UNX was performed when rats were 5 wk of age. Groups 0-4 were observed for 34 wk after which whole kidney clearance and morphologic studies were performed. Groups 5-8 underwent micropuncture study at 10 wk of age. Groups 4 and 8 were fed a diet containing $6 \%$ protein. All other rats ingested standard laboratory diet. 5 wk after UNX, normotensive group 6 had higher single nephron glomerular filtration rate (SNGFR) and initial glomerular plasma flow rate $\left(Q_{A}\right)$ than intact, hypertensive group 5 . Glomerular transcapillary hydraulic pressure difference $(\overline{\Delta P})$ was similar in these two groups. Hypertensive group 7 exhibited less elevation in SNGFR and $\mathbf{Q}_{\mathbf{A}}$ than group 6, but $\overline{\Delta P}$ was significantly increased. The presence of glomerular capillary hypertension in UNX SHR at 10 wk was associated with the development of significant proteinuria and an increased incidence of mesangial expansion and glomerular sclerosis at 7 mo (group 3) as compared with groups 0,1 , and 2. Protein restriction prevented the development of increased $\overline{\Delta \mathbf{P}}$ in UNX SHR (group 8 ) and also conferred long-term protection from increased urinary protein excretion and glomerular injury (group 4). These studies suggest that glomerular capillary hypertension predisposes to glomerular injury in this model of hypertension with reduced renal mass.
\end{abstract}

\section{Introduction}

Uncontrolled systemic hypertension is a well-known cause of progressive renal injury in both humans and experimental animals. However, the precise mechanism whereby elevation in arterial pressure leads to loss of renal function has not been elucidated. Traditionally, glomerular sclerosis and impaired renal function in patients with hypertension have been attributed to ischemia and underperfusion, secondary to primary structural damage to preglomerular arteries and arterioles. However, glo-

Portions of these studies were presented at the 16th Annual Meeting of the American Society of Nephrology, Washington, DC, December 1983, and have appeared in abstract form (1983. Am. Soc. Nephrol. 16:106A).

Address reprint requests to Dr. Dworkin, Department of Medicine, New York University Medical Center, 550 First Avenue, New York, NY 10016. 1985.

Received for publication 3 June 1985 and in revised form 6 October

J. Clin. Invest.

(c) The American Society for Clinical Investigation, Inc.

0021-9738/86/03/0797/13 $\$ 1.00$

Volume 77, March 1986, 797-809 merular sclerosis occurs in both Holtzman (1) and desoxycorticosterone-salt (DOC-SALT) ${ }^{1}(2)$ hypertensive rats where cortical micropuncture studies indicate that glomerular perfusion is increased. Studies in rats after extensive ablation of renal mass (3) suggest that such increases in capillary pressure and plasma flow rate may directly damage the glomerulus and lead to progressive renal insufficiency. In the DOC-SALT model of hypertension (2), augmented glomerular pressure and flow precede overt renal structural damage, and protein restriction protects rats from both hemodynamic and morphologic abnormalities. By analogy, glomerular hyperemia rather than ischemia might be responsible for renal injury in patients and animals with other forms of hypertension.

It is generally agreed that the spontaneously hypertensive rat strain (SHR) provides the best available animal analogue of essential hypertension in humans. SHR also develop glomerular sclerosis; however, the lesions occur primarily in juxtamedullary nephrons, making studies of relevant glomerular dynamics technically difficult. Uninephrectomy (UNX) increases glomerular capillary hydraulic pressure and plasma flow rate $(2,4)$ and exacerbates renal injury in a variety of models of renal disease (5-7). Accordingly, we reasoned that UNX might accelerate and extend hemodynamically mediated hypertensive damage to superficial cortical nephrons of SHR. We therefore correlated the hemodynamic and structural changes that occurred in the glomeruli of hypertensive SHR and control, normotensive WistarKyoto (WKY) rats that underwent UNX at 5 wk of age.

\section{Glossary}

$\overline{\mathrm{AP}} \quad$ mean femoral artery pressure, $\mathrm{mmHg}$

C protein concentration, $\mathrm{g} / 100 \mathrm{ml}$

GFR glomerular filtration rate (whole kidney), $\mathrm{ml} / \mathrm{min}$

Hct blood hematocrit in femoral artery, vol $/ 100 \mathrm{ml}$

$K_{\mathrm{f}} \quad$ glomerular capillary ultrafiltration coefficient, $\mathrm{nl} /$ $s \cdot m m H g$

$\mathrm{P} \quad$ hydraulic pressure, $\mathrm{mmHg}$

$\overline{\Delta \mathbf{P}} \quad$ glomerular transcapillary hydraulic pressure difference, $\overline{\mathrm{P}}_{\mathrm{GC}}-\mathrm{P}_{\mathrm{T}}, \mathrm{mmHg}$

ПI colloid osmotic pressure, $\mathrm{mmHg}$

$\Delta \Pi$ glomerular transcapillary oncotic pressure difference, $\Pi_{\mathrm{GC}}-\Pi_{\mathrm{T}}, m m H g$

Q arteriolar plasma flow, $\mathrm{nl} / \mathrm{min}$

RPF renal plasma flow (whole kidney), $\mathrm{ml} / \mathrm{min}$

$\mathrm{R}$ resistance to blood flow, dyne $\cdot \mathrm{s} \cdot \mathrm{cm}^{-5} \times 10^{10}$

SHR spontaneously hypertensive rat

SNFF single nephron filtration fraction

SNGFR single nephron glomerular filtration rate, $\mathrm{nl} / \mathrm{min}$

1. Abbreviations used in this paper: DOC-SALT, desoxycorticosterone salt; H \& E, hematoxylin and eosin stain; UNX, uninephrectomy; see Glossary for other abbreviations. 
unilateral nephrectomy

Wistar-Kyoto rat

\section{Superscript}

(overbar) mean value

\section{Subscripts}

A afferent arteriole

E efferent arteriole

GC glomerular capillary

$\mathrm{T}$ proximal tubule

\section{Methods}

Studies were performed in six groups of SHR and three groups of WKY (Taconic Farms, Inc., Germantown, NY) rats. As summarized in Table I, group $0(n=4)$ and group 1 rats $(n=6)$ were, respectively, intact WKY and SHR. Group 2 rats were WKY $(n=7)$ and group 3 were SHR $(n=7)$, both uninephrectomized at 5 wk of age. Rats in groups 0-3 were fed standard laboratory diet (Teklad), which contained 24\% protein by weight. Group 4 consisted of SHR $(n=6)$ uninephrectomized at 5 wk of age and fed a diet containing only $6 \%$ protein by weight, replete with electrolytes, trace minerals, and vitamins and supplemented with phosphate. Rats in groups $0-4$ were sacrificed at 34 wk of age. Rats in groups $5(n=8), 6(n=9), 7(n=10)$, and $8(n=12)$ were treated identically to rats in groups $1,2,3$, and 4 respectively, but were studied at 10 wk of age, 5 wk after nephrectomy in groups 6,7 , and 8 .

Whole kidney studies. Animals in groups $0-4$ were periodically placed in metabolic cages and 24 -h urine collections were made for determination of protein excretion rates. At $34 \mathrm{wk}$ of age, rats in groups 0-4 were anesthetized with Inactin $(100 \mathrm{mg} / \mathrm{kg}$ of body weight, i.p.) and prepared surgically for determination of inulin clearance. A tracheostomy was performed and polyethelene catheters were placed in the left and right jugular veins, left femoral artery, and ureter for infusion of solutions and collection of samples. To compensate for the loss of plasma associated with anesthesia and surgery, all rats received intravenous infusions of a volume of heparinized isoncotic rat plasma equal to $10 \mathrm{ml} / \mathrm{kg}$ of body weight for 20-30 min, followed by sustaining infusions of plasma at $\sim 0.5 \mathrm{ml} / \mathrm{h}$, adjusted to maintain hematocrit stable at baseline values. All rats also received a $0.5-\mathrm{ml}$ intravenous bolus of inulin $(7 \mathrm{~g} / 100 \mathrm{ml})$ in normal saline followed by a sustaining infusion of inulin at a rate of $1.0 \mathrm{ml} / \mathrm{h}$.

After a 45-min equilibration period, two 10-20-min timed urine collections were made. $100-\mu 1$ samples of femoral arterial blood were collected midway through each clearance period. Inulin concentration in urine and plasma samples was subsequently determined by the Anthrone method (8), and inulin clearance was calculated by the standard formula.

Urinary protein concentration was measured by precipitation with $3 \%$ sulfosalicylic acid. Turbity was then determined by measuring ab-

Table I. Summary of Groups and Protocols

\begin{tabular}{lrllll}
\hline Group & $n$ & Strain & UNX & Protein diet & Time of study \\
\hline & & & & $\%$ & $(w k)$ \\
0 & 4 & WKY & - & 24 & 34 \\
1 & 6 & SHR & - & 24 & 34 \\
2 & 7 & WKY & + & 24 & 34 \\
3 & 7 & SHR & + & 24 & 34 \\
4 & 6 & SHR & + & 6 & 34 \\
5 & 8 & SHR & - & 24 & 10 \\
6 & 9 & WKY & + & 24 & 10 \\
7 & 10 & SHR & + & 24 & 10 \\
8 & 12 & SHR & + & 6 & 10 \\
& & & & & \\
\hline
\end{tabular}

sorbance at a wavelength of $595 \mathrm{~nm}$ using a Coleman Junior II spectrophotometer. Urinary phosphate concentration was determined by the Fiske-Subbarow method (9).

Morphologic studies. After functional studies, the kidneys of animals from groups 0-4 were fixed by perfusion for $5 \mathrm{~min}$ at the measured arterial pressure with $1.25 \%$ glutaraldehyde in $0.1 \mathrm{M}$ cacodylate buffer (pH 7.4). Two coronal slices of each kidney, which included one pole and the middle portion, were processed routinely for light microscopy through paraffin embedding. Sections $3 \mu \mathrm{m}$ thick were stained with hematoxylin and eosin (H \& E). Selected periodic acid-Schiff- and silver methenamine-stained sections were also examined. The following glomerular abnormalities were quantitatively assessed in a blinded fashion by one observer using $\mathrm{H} \& \mathrm{E}$ sections: (a) mesangial expansion-characterized by an increase in cells and/or matrix, affecting one or more segments of a glomerulus (see Fig. $2 b$ ); (b) Segmental sclerosis-segmental collapse or obliteration of glomerular capillaries, increased basement membrane material, prominent visceral and/or parietal epithelial cells, capsular adhesion, and periglomerular fibrosis (see Fig. 2 c); (c) Global sclerosis-changes as described above affecting the entire glomerulus (see Fig. $2 d$ ). An average of 264 glomeruli (range 192-397) were examined in each rat. The percentage of glomeruli with mesangial expansion and glomerular sclerosis was calculated for each animal by dividing the number of abnormal glomeruli by the total number examined in that animal. Vascular and tubulointerstitial abnormalities were assessed in a nonquantitative manner.

For ultrastructural studies, $1-\mathrm{mm}^{3}$ pieces of cortex from at least two rats in each group were postfixed in osmium tetroxide and embedded in Epon. 1- $\mu \mathrm{m}$ sections stained with toluidine blue were used to select glomeruli for ultrastructural examination. It should be emphasized that abnormal glomeruli, when present, were selected for ultrastructural examination and thus the ultrastructural changes described below represent the most severe abnormalities found in each group. Ultrathin sections were stained on the grid using uranyl acetate and lead citrate and examined and photographed in a Zeiss EM 10A electron microscope (Carl Zeiss, Inc., Thornwood, NY).

Cortical micropuncture studies. Rats in groups 5-8 underwent micropuncture study at $10 \mathrm{wk}$ of age. Rats were anesthetized with Inactin $(100 \mathrm{mg} / \mathrm{kg}$ of body weight, i.p.) and prepared in the standard fashion for micropuncture (10). To compensate for losses resulting from anesthesia and surgery, these rats also received infusions of isoncotic rat plasma, in an identical fashion to that described above for the whole kidney studies. In addition, all rats received a $0.5-\mathrm{ml}$ intravenous bolus of $\left[{ }^{3} \mathrm{H}\right]$ methoxyinulin (New England Nuclear, Boston, MA) $(120 \mu \mathrm{Ci} /$ $\mathrm{ml}$ ) in normal saline followed by a sustaining infusion of inulin at a rate of $0.5 \mathrm{ml} / \mathrm{h}$.

Timed collections of proximal tubule fluid were obtained by micropuncture for determination of inulin content by liquid scintillation counting. Plasma and urine inulin concentrations were similarly determined and these measurements used to calculate SNGFR and whole kidney GFR by standard formulas (10). Efferent arteriolar blood samples were obtained for measurement of total protein concentration by the method of Viets et al. (11). Hydraulic pressure in cortical tubules and efferent arterioles was measured using the servo-null micropipette technique (10). Mean glomerular capillary hydraulic pressure was estimated by stop-flow techniques, as described by Allison et al. (12). Calculation of the determinants of glomerular ultrafiltration and vascular resistances were made using standard formulas as set out by Baylis et al. (10).

Analysis of data. Statistical analysis was performed by one-way analysis of variance followed by computation of modified $t$ values and multiple pairwise comparisons according to the method of Bonferroni (13). Statistical significance was defined as $P<0.05$.

\section{Results}

\section{Whole kidney clearance studies}

Mean values for body weight, Hct, $\overline{\mathrm{AP}}$, whole kidney GFR, and perfused kidney weight of rats in groups $0-4$ at the time of sac- 
rifice are given in Table II. All rats gained weight during the 29 wk between randomization and sacrifice; however, on average, protein-restricted rats in group 4 weighed significantly less than rats in each of the other groups at the time of sacrifice. $\overline{\mathrm{AP}}$ was significantly elevated in all SHR groups as compared to intact and UNX WKY rats in groups 0 and 2. Protein restriction did not significantly affect $\overline{\mathrm{AP}}$ in UNX SHR as mean values in groups 3 and 4 were not statistically different. Inulin clearance for a single kidney was not significantly increased by UNX in either WKY or SHR rats. In WKY rats, this may have resulted, at least in part, from the fact rats in group 0 gained significantly more weight than those in group 2 . When factored for body weight, inulin clearance was increased significantly in UNX WKY rats, from a mean value of $0.40 \pm 0.07$ in group 0 to $0.58 \pm 0.01 \mathrm{ml} / \mathrm{min}$ per $100 \mathrm{~g}$ rat body weight in group 2 . However, even when factored for body weight, inulin clearance was similar in intact and UNX SHR, averaging $0.41 \pm 0.002$ in group 1 and $0.42 \pm 0.01 \mathrm{ml} / \mathrm{min}$ in group 3 . This failure of GFR to increase after UNX in SHR may have resulted from the fact that significant morphologic evidence of renal injury was present in group 3 rats at this age. Protein restriction reduced the mean value for GFR in group 4, although this lower value was not significantly different than that measured in group 3. UNX caused kidney weight to increase numerically in WKY and significantly in SHR rats. Protein restriction completely prevented the hypertrophic response to UNX in SHR as kidney weight averaged only $1.791 \pm 0.050 \mathrm{~g}$ in group 4 , a value significantly less than that observed in group 3 and not different from that observed in group 1.

Mean values for 24-h urinary protein excretion at several times during the 34-wk study period are displayed in Fig. 1. For groups 2-4, protein excretion was determined at 7, 16, 23, 27, 32 , and $34 \mathrm{wk}$ of age. For rats in groups 0 and 1, measurements were made at only 23,27 , and $32 \mathrm{wk}$. By $23 \mathrm{wk}$ of age, average protein excretion rate in UNX SHR (group 3, 29.8 $\pm 2.5 \mathrm{mg} / 24$

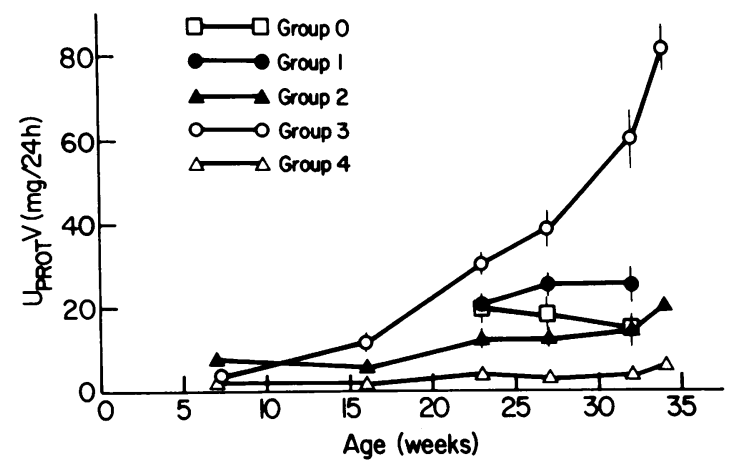

Figure 1. 24-h urinary protein excretion measured at several times during the study period in rats in groups $0-4$. All symbols represent means \pm SEM. Groups are defined in Table I.

h) significantly exceeded $(P<0.05)$ that observed in group 0 (19.2 \pm 2.8$)$, group $1(20.5 \pm 2.2)$, group $2(12.2 \pm 1.4)$, and group $4(4.3 \pm 0.9)$. This trend continued so that by the time of the final urine collection at $34 \mathrm{wk}$, protein excretion was $81.4 \pm 5.4 \mathrm{mg} /$ $24 \mathrm{~h}$ in group 3, greatly exceeding the values of $19.9 \pm 0.9$ in group 2, 24.8 \pm 3.6 in group 1, and 15.0 \pm 0.7 in group 0. Importantly, protein restriction completely prevented the development of proteinuria in UNX SHR, as rats in group 4 excreted only $5.6 \pm 0.5 \mathrm{mg}$ of protein in $24 \mathrm{~h}$ at $34 \mathrm{wk}$ of age, significantly less than groups 0 to 3 , despite the fact that these rats had similar increases in systemic arterial blood pressure as compared with UNX SHR fed normal chow (group 3).

Determination of urinary phosphate excretion rates revealed that rats in all five groups excreted similar amounts of inorganic phosphate in $24 \mathrm{~h}$. Mean values were $0.35 \pm 0.08 \mathrm{mmol} / 24 \mathrm{~h}$ in group 0, $0.11 \pm 0.02$ in group $1,0.21 \pm 0.04$ in group 2, 0.29 \pm 0.17 in group 3 , and $0.62 \pm 0.26$ in group 4 . These values were not statistically different.

Table II. Summary of Whole Kidney Clearance Studies

\begin{tabular}{|c|c|c|c|c|c|}
\hline Group & Body weight & Het & $\overline{\mathrm{AP}}$ & Inulin clearance & Kidney weight \\
\hline & $g$ & $\%$ & $m m H g$ & $\mathrm{ml} / \mathrm{min}$ & $g$ \\
\hline $0(n=4)$ & $553 \pm 20$ & $42 \pm 0.2$ & $120 \pm 3$ & $2.28 \pm 0.45$ & $2.678 \pm 0.050$ \\
\hline $1(n=6)$ & $369 \pm 6$ & $46 \pm 1$ & $208 \pm 2$ & $1.52 \pm 0.07$ & $1.774 \pm 0.050$ \\
\hline $2(n=7)$ & $383 \pm 6$ & $42 \pm 1$ & $117 \pm 4$ & $2.25 \pm 0.12$ & $3.026 \pm 0.100$ \\
\hline $3(n=7)$ & $401 \pm 5$ & $45 \pm 1$ & $174 \pm 3$ & $1.74 \pm 0.13$ & $3.099 \pm 0.116$ \\
\hline $4(n=6)$ & $334 \pm 10$ & $49 \pm 1$ & $178 \pm 6$ & $1.17 \pm 0.06$ & $1.791 \pm 0.050$ \\
\hline \multicolumn{6}{|c|}{ Probability* } \\
\hline 0 vs. 1 & $*$ & NS & $*$ & $*$ & $*$ \\
\hline 0 vs. 2 & $*$ & NS & NS & NS & NS \\
\hline 0 vs. 3 & $*$ & NS & $*$ & NS & NS \\
\hline 0 vs. 4 & $*$ & $*$ & $*$ & $*$ & $*$ \\
\hline 1 vs. 2 & NS & $*$ & $*$ & $*$ & $*$ \\
\hline 1 vs. 3 & $*$ & NS & $*$ & NS & $*$ \\
\hline 1 vs. 4 & $*$ & NS & $*$ & NS & NS \\
\hline 2 vs. 3 & NS & NS & $*$ & NS & NS \\
\hline 2 vs. 4 & $*$ & $*$ & $*$ & $*$ & $*$ \\
\hline 3 vs. 4 & $*$ & $*$ & NS & $P=0.06$ & $*$ \\
\hline
\end{tabular}

Data are given as mean \pm standard error of the mean. Inulin clearance is given for one kidney. ${ }^{*} P<0.05$. NS, not significant. 


\section{Micropuncture studies}

Mean values for body weight; Hct; whole kidney GFR; $\overline{\mathrm{AP}}$; SNGFR; and the pressures, flows, and resistances governing glomerular ultrafiltration for animals in groups 5-8 are summarized in Table III. At 10 wk of age, $\overline{\mathrm{AP}}$ was already increased by $\sim 50 \%$ in all SHR groups $(5,7$, and 8$)$ as compared with UNX WKY rats in group 6. In intact SHR, this increase in systemic arterial pressure was not transmitted to the glomerular capillaries, as mean values for $\overline{\mathrm{P}}_{\mathrm{GC}}$ and $\overline{\Delta \mathrm{P}}$ for group 5 were similar to those found in normotensive WKY rats in group 6 . In contrast, uninephrectomy lead to significant increases in both $\overline{\mathrm{P}}_{\mathrm{GC}}$ and $\overline{\Delta \mathrm{P}}$ in SHR fed standard laboratory diet, which were increased by $9 \mathrm{mmHg}$ over corresponding values measured in intact SHR (group 5).

Mean values for GFR, SNGFR, and $Q_{A}$ were all greater in group 6 than in group 5 rats. As values for $C_{A}$ were not different in these two groups, the increased filtration rate in UNX WKY rats was partly the result of the observed increase in $Q_{A}$, but also the result of a calculated $73 \%$ greater value for $K_{f}$ in group 6 than in group 5 rats. The increase in plasma flow in group 6 was the result of significantly lower values for afferent, efferent, and total resistance as compared with group 5.

In addition to causing elevations in $\overline{\mathrm{P}}_{\mathrm{GC}}$ and $\overline{\Delta \mathrm{P}}, \mathrm{UNX}$ in SHR resulted in a $50 \%$ increase $Q_{A}$ in group 7 over group 5 rats. This value was still $\sim 24 \%$ less than corresponding value measured in UNX WKY rats in group 6. The observed increases in glomerular capillary pressure and flow led to a significant, $50 \%$ increase in SNGFR in group 7 compared to intact SHR in group 5. This value for SNGFR was nevertheless $22 \%$ lower than the value measured in group 6 rats, a consequence of the lesser increase in $\mathrm{Q}_{\mathrm{A}}$ as well as a $42 \%$ lower value for $K_{\mathrm{f}}$ in UNX SHR as compared with WKY rats. Whole kidney GFR was also intermediate in group 7 when compared to groups 5 and 6 . The increases in flow and pressure within glomerular capillaries of group 7 as compared with group 5 rats were the result of a selective, 37\% reduction in afferent arteriolar resistance after uninephrectomy.

Despite similar, significant elevation in systemic arterial pressure, micropuncture study revealed a strikingly different glomerular hemodynamic pattern in UNX SHR ingesting the low protein diet (group 8) than in those fed normal chow (group 7). $\overline{\mathrm{P}}_{\mathrm{GC}}$ was reduced by $6 \mathrm{mmHg}$ in group 8 rats, to a value not significantly different from that observed in groups 5 and 6. Because of a small but statistically significant elevation in $P_{\mathrm{T}}$ in group 8 rats to $15 \mathrm{mmHg}, \overline{\Delta \mathrm{P}}$ was only $1 \mathrm{mmHg}$ greater in this group than in groups 5 and 6 , and $8 \mathrm{mmHg}$ less than that seen in group 7. $\mathrm{C}_{\mathrm{A}}$ was modestly but significantly decreased in group 8 , compared to groups 5-7. Low protein feeding also resulted in reduction in $Q_{A}, S N G F R$, and GFR in group 8 rats, to values that were not different from those in intact SHR in group 5 but less than those in either of the other nephrectomized groups. $\overline{\mathrm{P}}_{\mathrm{GC}}$ and $\mathrm{Q}_{\mathrm{A}}$ were reduced in group 8 rats as a consequence of a $106 \%$ increase in afferent and a $130 \%$ increase in efferent arteriolar resistance in UNX SHR eating $6 \%$ as opposed to $24 \%$ protein chow. Resistances in group 8 rats were similar to those calculated for intact SHR in group 5, and demonstrate the mechanism by which low protein feeding completely prevented the intrarenal hemodynamic consequences of UNX.

\section{Morphologic studies}

Light microscopy. At $34 \mathrm{wk}$ of age, mesangial expansion and glomerular sclerosis were present in renal tissue from rats in groups 0-4. However, there were significant differences in the incidence of these lesions in each of the five groups. As shown in Table IV, mesangial expansion involved significantly more glomeruli in group 3 animals as compared to groups $0,1,2$, and

Table III. Summary of Renal Cortical Microcirculation Studies

\begin{tabular}{|c|c|c|c|c|c|c|c|c|c|c|c|}
\hline Group & $\begin{array}{l}\text { Body } \\
\text { weight }\end{array}$ & Hct & $\overline{\mathrm{AP}}$ & $\overline{\mathrm{P}}_{\mathrm{OC}}$ & $\mathbf{P}_{\mathbf{T}}$ & $\mathbf{P}_{\mathbf{E}}$ & $\overline{\Delta \mathrm{P}}$ & $\Pi_{E}$ & $\mathrm{C}_{\mathrm{A}}$ & $C_{E}$ & $\Pi_{\mathrm{E}} / \overline{\Delta \mathrm{P}}$ \\
\hline & $g$ & $\%$ & $m m H g$ & $\mathrm{mmHg}$ & $\mathrm{mmHg}$ & $\mathrm{mmHg}$ & $\mathrm{mmHg}$ & $\mathrm{mmHg}$ & $\mathrm{g} / 100 \mathrm{ml}$ & $\mathrm{g} / 100 \mathrm{ml}$ & \\
\hline 5 & $\begin{array}{l}277 \pm 5 \\
(8)\end{array}$ & $\begin{array}{l}48 \pm 1 \\
(8)\end{array}$ & $\begin{array}{l}162 \pm 5 \\
(8)\end{array}$ & $\begin{array}{l}54 \pm 1 \\
(8)\end{array}$ & $\begin{array}{l}13 \pm 1 \\
(8)\end{array}$ & $\begin{array}{l}15 \pm 1 \\
(8)\end{array}$ & $\begin{array}{l}41 \pm 2 \\
(8)\end{array}$ & $\begin{array}{l}40 \pm 2 \\
(8)\end{array}$ & $\begin{array}{l}5.6 \pm 0.1 \\
(8)\end{array}$ & $\begin{array}{l}9.1 \pm 0.3 \\
(8)\end{array}$ & $\begin{array}{l}0.95 \pm 0.02 \\
(8)\end{array}$ \\
\hline 6 & $\begin{array}{l}278 \pm 13 \\
(9)\end{array}$ & $\begin{array}{l}43 \pm 1 \\
(9)\end{array}$ & $\begin{array}{l}109 \pm 3 \\
(9)\end{array}$ & $\begin{array}{l}53 \pm 2 \\
(9)\end{array}$ & $\begin{array}{l}12 \pm 1 \\
(9)\end{array}$ & $\begin{array}{l}16 \pm 1 \\
(9)\end{array}$ & $\begin{array}{l}41 \pm 2 \\
(9)\end{array}$ & $\begin{array}{l}36 \pm 1 \\
(8)\end{array}$ & $\begin{array}{l}5.5 \pm 0.1 \\
(9)\end{array}$ & $\begin{array}{l}8.6 \pm 0.2 \\
(8)\end{array}$ & $\begin{array}{l}0.89 \pm 0.05 \\
(8)\end{array}$ \\
\hline 7 & $\begin{array}{l}261 \pm 6 \\
(10)\end{array}$ & $\begin{array}{l}46 \pm 1 \\
(10)\end{array}$ & $\begin{array}{l}164 \pm 4 \\
(10)\end{array}$ & $\begin{array}{l}63 \pm 1 \\
(10)\end{array}$ & $\begin{array}{l}13 \pm 1 \\
(10)\end{array}$ & $\begin{array}{l}14 \pm 1 \\
(10)\end{array}$ & $\begin{array}{l}50 \pm 1 \\
(10)\end{array}$ & $\begin{array}{l}41 \pm 2 \\
(10)\end{array}$ & $\begin{array}{l}5.8 \pm 0.1 \\
(10)\end{array}$ & $\begin{array}{l}9.3 \pm 0.2 \\
(10)\end{array}$ & $\begin{array}{l}0.82 \pm 0.04 \\
(10)\end{array}$ \\
\hline 8 & $\begin{array}{l}212 \pm 6 \\
(12)\end{array}$ & $\begin{array}{l}44 \pm 1 \\
(12)\end{array}$ & $\begin{array}{l}166 \pm 4 \\
(12)\end{array}$ & $\begin{array}{l}57 \pm 1 \\
(10)\end{array}$ & $\begin{array}{l}15 \pm 1 \\
(10)\end{array}$ & $\begin{array}{l}16 \pm 1 \\
(10)\end{array}$ & $\begin{array}{l}42 \pm 1 \\
(10)\end{array}$ & $\begin{array}{l}30 \pm 1 \\
(12)\end{array}$ & $\begin{array}{l}5.2 \pm 0.1 \\
(12)\end{array}$ & $\begin{array}{l}7.7 \pm 0.2 \\
(12)\end{array}$ & $\begin{array}{l}0.73 \pm 0.03 \\
(10)\end{array}$ \\
\hline \multicolumn{12}{|c|}{ Probability* } \\
\hline 5 vs. 6 & NS & $*$ & $*$ & NS & NS & NS & NS & NS & NS & NS & NS \\
\hline 5 vs. 7 & NS & NS & NS & $*$ & NS & NS & $*$ & NS & NS & NS & NS \\
\hline 5 vs. 8 & $*$ & $*$ & NS & NS & $*$ & NS & NS & $*$ & $*$ & $*$ & $*$ \\
\hline 6 vs. 7 & NS & $*$ & $*$ & $*$ & NS & NS & $*$ & NS & $*$ & NS & NS \\
\hline 6 vs. 8 & $*$ & NS & $*$ & NS & $*$ & NS & NS & $*$ & $*$ & $*$ & NS \\
\hline 7 vs. 8 & $*$ & NS & NS & $*$ & $*$ & NSS & $*$ & $*$ & $*$ & $*$ & NS \\
\hline
\end{tabular}

Data are given as mean \pm standard error of the mean. Numbers in parentheses indicate number of rats in which data were obtained. ${ }^{*} P<0.05$. NS, not significant. $¥$ Value is a mean of exact values calculated in all but two rats (six of eight) and minimum values calculated for those two remaining rats (two of eight). 
4. In all groups this change was uniformly distributed throughout the thickness of the cortex. In contrast to normal glomerular morphology shown in Fig. $2 a$, mesangial expansion distributed segmentally and globally are shown in Figs. $2 b$ and $c$, respectively. Sclerosis also involved significantly more glomeruli in group 3 as compared to group $0,1,2$, and 4 animals. However, in contrast to mesangial expansion, sclerosis involved predominantly the juxtamedullary glomeruli. Segmental and global sclerosis of glomeruli are illustrated in Figs. $2 c$ and $d$, respectively. It should be noted that lesions of both segmental and global sclerosis were characterized by shrinkage but not complete capillary obliteration of the involved segment(s). Indeed, erythrocytes, which were preferentially retained in such glomeruli of otherwise well-perfused kidneys, were evidence of some circulation through these glomeruli.

Only hypertensive animals displayed changes in blood vessels. Muscular hypertrophy of arteries and arterioles (Fig. $2 e$ ) was present in three of six animals in group 3 and six of six animals in group 4 . Three of the latter group also showed fibrinoid changes in the medias of small arteries and arterioles (Fig. $2 f$ ). Thus, unlike glomerular changes, vascular changes were not ameliorated, but in fact were exacerbated, by protein restricting the hypertensive animals. This observation is consistent with the hemodynamic finding that low protein feeding reduced glomerular capillary but not systemic arterial pressure in UNX SHR.

Tubulointerstitial changes characterized by atrophy, dilation, acellular casts, interstitial inflammation, and fibrosis were much more marked in group 3 as compared to groups $0,1,2$, and 4 . These changes were most pronounced in the region of the corticomedullary junction.

Electron microscopy. Renal tissue from two to three animals of groups 2-4 was examined. Four to eight glomeruli in each animal were examined in toluidine blue-stained survey sections. The majority of glomeruli in all groups appeared normal. Glomeruli with mesangial expansion were found in renal tissue from group 3 and 4 rats, but not from group 2. A single glomerulus with segmental sclerosis was found in one group 3 animal. These glomeruli were subsequently examined by electron microscopy. Mild increases in mesangial cells and matrix were easily recognized when contrasted with normal glomeruli (Fig. 3). Walls of capillaries subtended by such mesangial regions were unremarkable. More marked mesangial expansion was characterized by a disproportional increase in matrix as compared to cells, and deposition of collagen in the matrix (Fig. 4). Capillaries subtended by such mesangial regions showed irregular thickening of the endothelial cytoplasm and reduction of fenestrae, basement membrane thickening, and obliteration of epithelial cell foot processes.

\section{Discussion}

Feld and associates (14) first correlated measurements of tubular and urinary protein content with assessments of kidney function and morphology in spontaneously hypertensive rats and their normotensive controls, Wistar-Kyoto rats. At $\sim 1$ yr of age, SHR had elevated serum creatinine and urinary excretion of albumin and reduced creatinine clearance, in association with histologic abnormalities of the kidney, including glomerular sclerosis and obliteration. These morphologic lesions appeared first in the deep, juxtamedullary nephrons of SHR. Superficial cortical nephrons were relatively spared both histologically and functionally, as filtrate collected from surface tubules contained little albumin, despite the presence of significant quantities of protein in the final urine. Normotensive WKY rats had neither proteinuria nor histologic evidence of renal injury.

Table III. (Continued)

\begin{tabular}{|c|c|c|c|c|c|c|c|}
\hline SNFF & SNGFR & $\mathrm{Q}_{A}$ & $K_{\mathrm{f}}$ & GFR & $\mathbf{R}_{\mathbf{A}}$ & $\mathbf{R}_{\mathbf{E}}$ & $\mathbf{R}_{\mathbf{T}}$ \\
\hline & $n l / m i n$ & $n l / m i n$ & $n l / s \cdot m m H g$ & $\mathrm{ml} / \mathrm{min}$ & dyne $\cdot \mathrm{s} \cdot \mathrm{cm}^{-5} \times 10^{10}$ & dyne $\cdot \mathrm{s} \cdot \mathrm{cm}^{-5} \times 10^{10}$ & dyne $\cdot \mathrm{s} \cdot \mathrm{cm}^{-5} \times 10^{10}$ \\
\hline $\begin{array}{l}0.38 \pm 0.02 \\
(8)\end{array}$ & $\begin{array}{l}41.8 \pm 2.7 \\
(8)\end{array}$ & $\begin{array}{l}113 \pm 9 \\
(8)\end{array}$ & $\begin{array}{l}0.059 \pm 0.006 \ddagger \\
(8)\end{array}$ & $\begin{array}{l}1.11 \pm 0.10 \\
(8)\end{array}$ & $\begin{array}{l}4.15 \pm 0.30 \\
(8)\end{array}$ & $\begin{array}{l}1.98 \pm 0.25 \\
(8)\end{array}$ & $\begin{array}{l}6.13 \pm 0.51 \\
(8)\end{array}$ \\
\hline $\begin{array}{l}0.37 \pm 0.01 \\
(9)\end{array}$ & $\begin{array}{l}76.3 \pm 3.8 \\
(8)\end{array}$ & $\begin{array}{l}211 \pm 11 \\
(8)\end{array}$ & $\begin{array}{l}0.102 \pm 0.017 \ddagger \\
(8)\end{array}$ & $\begin{array}{l}1.83 \pm 0.24 \\
(9)\end{array}$ & $\begin{array}{l}1.23 \pm 0.09 \\
(8)\end{array}$ & $\begin{array}{l}1.07 \pm 0.10 \\
(8)\end{array}$ & $\begin{array}{l}2.30 \pm 0.11 \\
(8)\end{array}$ \\
\hline $\begin{array}{l}0.37 \pm 0.02 \\
(10)\end{array}$ & $\begin{array}{l}62.6 \pm 4.2 \\
(10)\end{array}$ & $\begin{array}{l}170 \pm 11 \\
(10)\end{array}$ & $\begin{array}{l}0.059 \pm 0.007 \\
(10)\end{array}$ & $\begin{array}{l}1.51 \pm 0.09 \\
(10)\end{array}$ & $\begin{array}{l}2.62 \pm 0.17 \\
(10)\end{array}$ & $\begin{array}{l}1.60 \pm 0.12 \\
(10)\end{array}$ & $\begin{array}{l}4.23 \pm 0.27 \\
(10)\end{array}$ \\
\hline $\begin{array}{l}0.33 \pm 0.01 \\
(12)\end{array}$ & $\begin{array}{l}33.2 \pm 2.0 \\
(12)\end{array}$ & $\begin{array}{l}104 \pm 8 \\
(12)\end{array}$ & $\begin{array}{l}0.030 \pm 0.003 \\
(10)\end{array}$ & $\begin{array}{l}0.90 \pm 0.06 \\
(12)\end{array}$ & $\begin{array}{l}5.40 \pm 0.72 \\
(10)\end{array}$ & $\begin{array}{l}2.46 \pm 0.30 \\
(10)\end{array}$ & $\begin{array}{l}7.86 \pm 1.02 \\
(10)\end{array}$ \\
\hline NS & * & * & $*$ & $*$ & * & $*$ & $*$ \\
\hline NS & $*$ & $*$ & NS & NS & $*$ & NS & NS \\
\hline NS & NS & NS & NS & NS & NS & NS & NS \\
\hline NS & $*$ & $*$ & $*$ & NS & NS & NS & NS \\
\hline NS & $*$ & $*$ & $*$ & $*$ & $*$ & $*$ & $*$ \\
\hline NS & $*$ & $*$ & NS & $*$ & * & $*$ & $*$ \\
\hline
\end{tabular}




\begin{tabular}{|c|c|c|c|c|c|c|c|}
\hline \multirow{3}{*}{ Group } & \multirow{3}{*}{ Rat } & \multirow{3}{*}{$\begin{array}{l}\begin{array}{l}\text { Glomeruli } \\
\text { examined }\end{array} \\
n\end{array}$} & & & \multicolumn{3}{|l|}{ Sclerosis } \\
\hline & & & Mes: & & \multirow{2}{*}{$\begin{array}{l}\text { Segmental } \\
n\end{array}$} & \multicolumn{2}{|c|}{ Global } \\
\hline & & & $n$ & $\%$ & & $n$ & $\%$ \\
\hline \multirow[t]{5}{*}{0} & 1 & 214 & 13 & 6 & 0 & 1 & 0.5 \\
\hline & 2 & 215 & 15 & 7 & 0 & 0 & 0 \\
\hline & 3 & 219 & 10 & 5 & 0 & 0 & 0 \\
\hline & 4 & 220 & 18 & 8 & 0 & 0 & 0 \\
\hline & Mean & $217 \pm 1$ & & $6 \pm 1$ & & & $0.1 \pm 0.1$ \\
\hline \multirow[t]{7}{*}{1} & 1 & 246 & 46 & 19 & 0 & 1 & 0.4 \\
\hline & 2 & 192 & 33 & 17 & 0 & 1 & 0.5 \\
\hline & 3 & 202 & 51 & 25 & 0 & 3 & 1.5 \\
\hline & 4 & 214 & 33 & 15 & 0 & 2 & 0.9 \\
\hline & 5 & 208 & 24 & 12 & 0 & 2 & 1.0 \\
\hline & 6 & 223 & 19 & 9 & 0 & 0 & 0 \\
\hline & Mean & $214 \pm 7$ & & $16 \pm 2$ & & & $0.8 \pm 0.2$ \\
\hline \multirow[t]{8}{*}{2} & 1 & 220 & 26 & 12 & 0 & 1 & 0.4 \\
\hline & 2 & 247 & 13 & 5 & 0 & 1 & 0.4 \\
\hline & 3 & 245 & 21 & 8 & 2 & 0 & 0.8 \\
\hline & 4 & 254 & 35 & 14 & 1 & 0 & 0.4 \\
\hline & 5 & 237 & 26 & 10 & 0 & 1 & 0.4 \\
\hline & 6 & 210 & 17 & 8 & 1 & 0 & 0.5 \\
\hline & 7 & 309 & 18 & 6 & 0 & 0 & 0 \\
\hline & Mean & $246 \pm 11$ & & $9 \pm 1$ & & & $0.4 \pm 0.0$ \\
\hline \multirow[t]{7}{*}{3} & 1 & 280 & 70 & 25 & 11 & 4 & 5.4 \\
\hline & 2 & 287 & 37 & 13 & 4 & 2 & 2.1 \\
\hline & 3 & 289 & 59 & 20 & 8 & 3 & 3.8 \\
\hline & 4 & 397 & 92 & 32 & 7 & 14 & 5.3 \\
\hline & 5 & 281 & 75 & 26 & 11 & 13 & 8.5 \\
\hline & 6 & 339 & 86 & 26 & 9 & 12 & 6.2 \\
\hline & Mean & $312 \pm 18$ & & $24 \pm 2$ & & & $5.2 \pm 0.8$ \\
\hline \multirow[t]{7}{*}{4} & 1 & 292 & 35 & 11 & 2 & 1 & 1.0 \\
\hline & 2 & 243 & 48 & 20 & 0 & 2 & 0.8 \\
\hline & 3 & 320 & 35 & 13 & 1 & 2 & 0.9 \\
\hline & 4 & 259 & 16 & 7 & 0 & 1 & 0.4 \\
\hline & 5 & 294 & 25 & 8 & 0 & 0 & 0 \\
\hline & 6 & 302 & 20 & 7 & 0 & 0 & 0 \\
\hline & Mean & $285 \pm 11$ & & $11 \pm 2$ & & & $0.5 \pm 0.2$ \\
\hline
\end{tabular}

Probability*

$\begin{array}{llll}0 \text { vs. } 1 & \text { NS } & * & \text { NS } \\ 0 \text { vs. } 2 & \text { NS } & * & \text { NS } \\ 0 \text { vs. } 3 & * & \text { NS } & \text { NS } \\ 0 \text { vs. } 4 & \text { NS } & * & \text { NS } \\ 1 \text { vs. } 2 & * & * & \text { NS } \\ 1 \text { vs. } 3 & * & \text { NS } & * \\ 1 \text { vs. } 4 & * & * & \text { NS } \\ 2 \text { vs. } 3 & \text { NS } & \text { NS } & * \\ 2 \text { vs. } 4 & \text { NS } & * & \text { NS } \\ 3 \text { vs. } 4 & & & *\end{array}$

Values indicate numbers of glomeruli except where indicated; data for mean values are given as mean \pm standard error of the mean. ${ }^{*} P<0.05$. NS, not significant. 

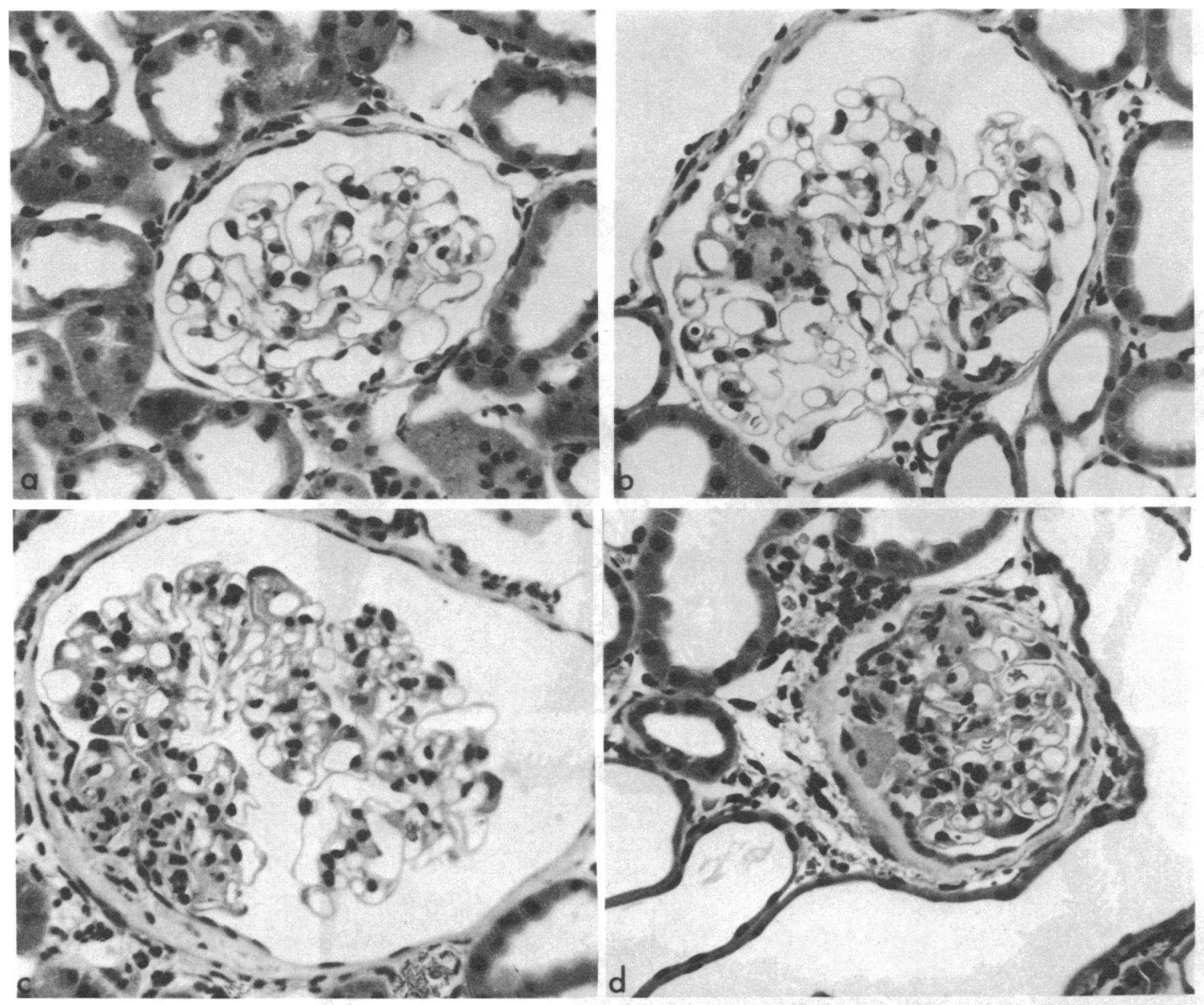

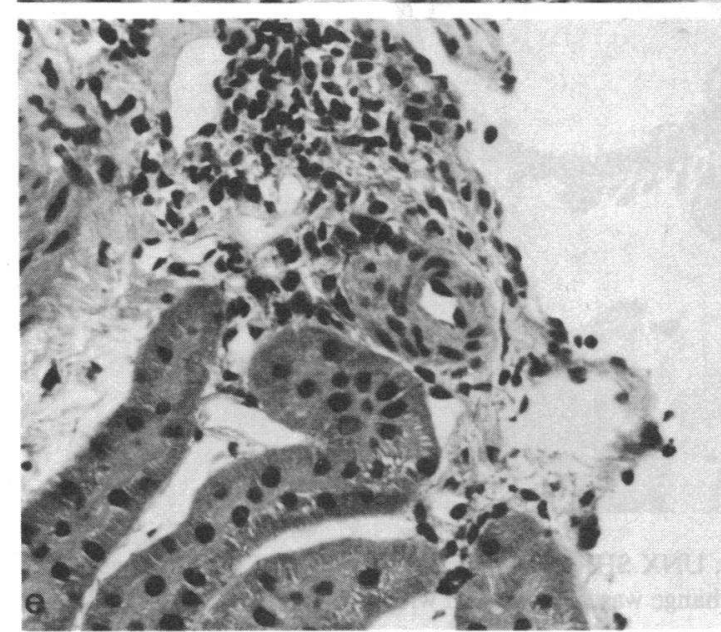

Figure 2. Light micrographs of renal cortex. Representative light micrographs taken from rats in groups $1-4$ at $34 \mathrm{wk}$. Sections $3 \mu \mathrm{m}$ thick were stained with H \& E $(\times 600)$. (a) Normal glomerulus, UNX WKY rat (group 2). (b) Glomerulus with segmental mesangial hypercellularity and increased matrix, UNX SHR, 24\% protein diet (group 3 ). $\sim 25 \%$ of glomeruli of group 3 rats had mesangial expansion. (c) Global mesangial expansion and segmental sclerosis, UNX SHR

In the present study, unilateral nephrectomy dramatically accelerated the course of renal damage in SHR. Significant proteinuria was observed in UNX SHR at 23 wk of age, only 18

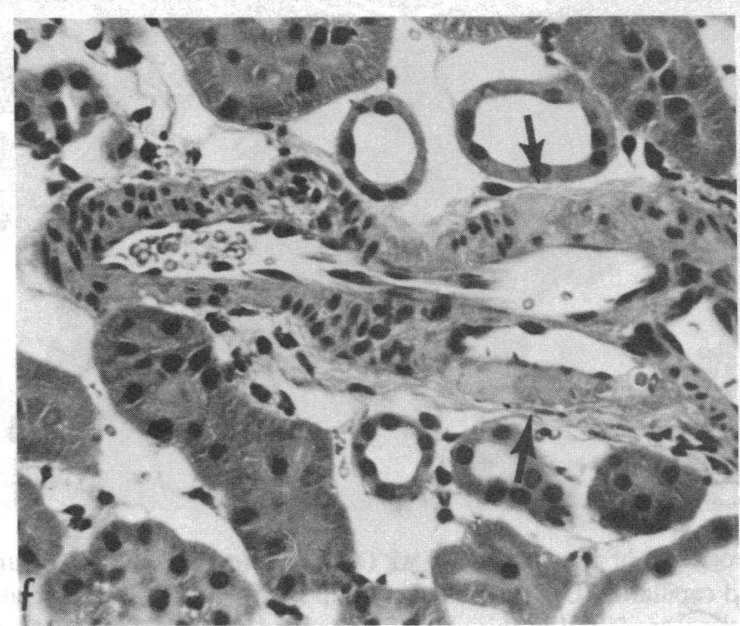

(group 3). (d) Global sclerosis of a juxtamedullary glomerulus, periglomerular fibrosis, and inflammation, UNX SHR (group 3). 5\% of glomeruli of group 3 rats were sclerotic. (e) Arterial medial hypertrophy as shown here was present in six of six UNX SHR on the 6\% protein diet (group 4). ( $f$ ) Artery with medial fibrinoid change (arrows). This lesion was present in three of six group 4 rats.

wk after nephrectomy and 13 wk after the onset of signficant elevation in arterial pressure (Fig. 1). Bank et al. (15) have reported similar findings. More important than this acceleration 


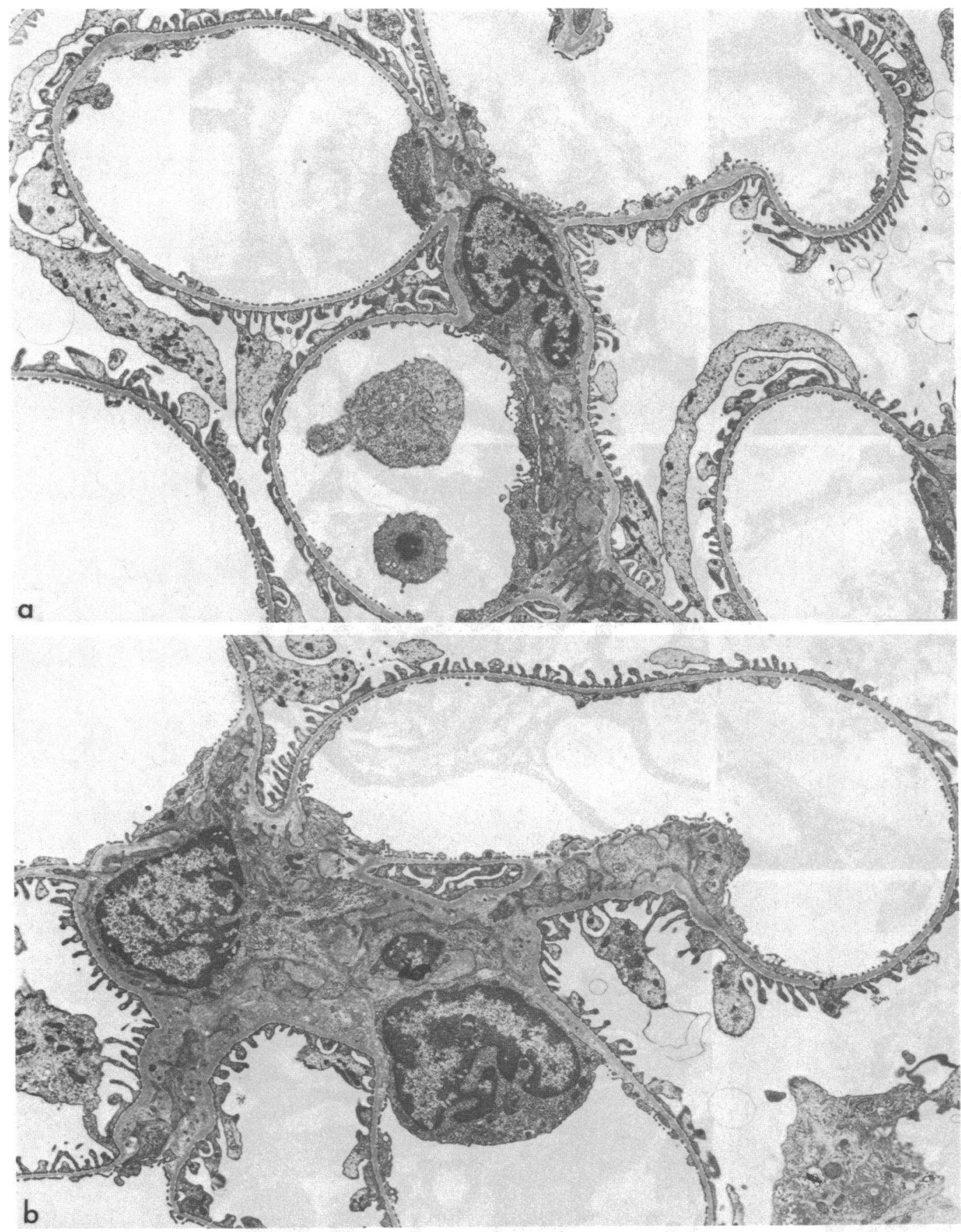

Figure 3. Electron micrographs of glomeruli at 34 wk $(\times 4,000)$. (a) Normal mesangium and capillaries, UNX WKY rat (group 2). No ultrastructural abnormalities were found in this group. (b) Expanded

in the pace of renal injury for our analysis, was the fact that UNX produced more widespread glomerular damage, so that by 35 wk of age, superficial as well as deep nephrons displayed structural changes. Nevertheless, some stratification of injury was evident in our rats, inasmuch as tubulo-interstitial changes and glomerular sclerosis were most prominent in the juxtamedullary cortex. Whether glomerular sclerosis was à sequel to mesangial expansion or an unrelated lesion could not be ascertained with certainty.

Whole kidney clearance studies performed on rats at $7 \frac{1}{2} \mathrm{mo}$ of age failed to provide an explanation for the increase in glo- mesangium, UNX SHR on 24\% protein diet (group 3). This degree of mesangial change was unassociated with glomerular capillary wall abnormalities.

merular injury observed in SHR after UNX. At that time, GFR was lower in SHR than in UNX WKY, again similar to the report of Bank et al. (15). In that study, average values for SNGFR and $Q_{A}$ were also lower in UNX SHR than in UNX WKY rats at 6 mo of age. Furthermore, glomerular capillary pressure was not different in these two groups of rats. Based upon these observations, Bank et al. (15) concluded that alterations in superficial glomerular dynamics did not account for glomerular injury in UNX SHR.

In the present study, micropuncture was performed much earlier in the natural history of hypertensive nephrosclerosis in 


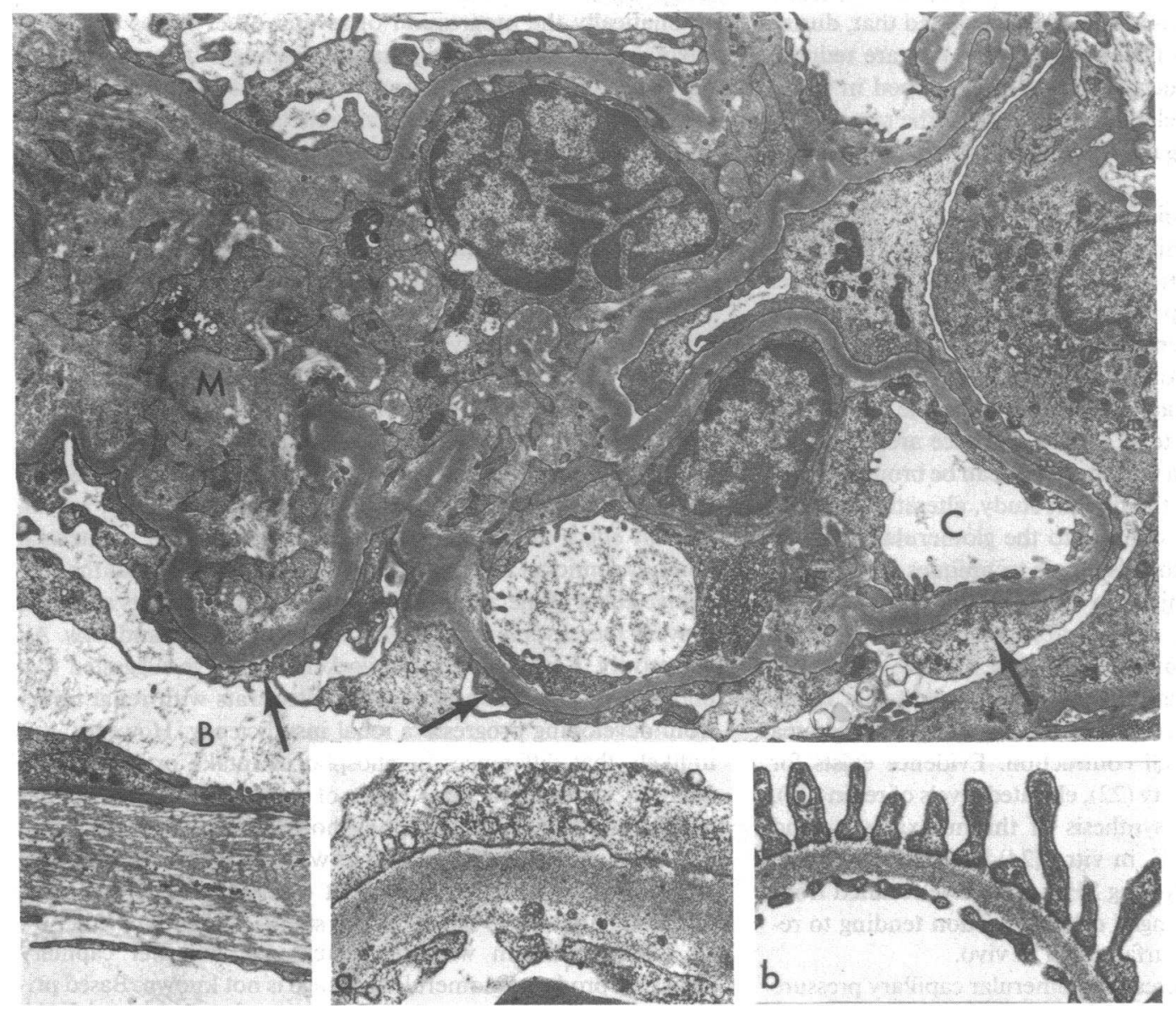

Figure 4. Electron micrograph of a segmental sclerosing lesion in a UNX SHR (group 3) at 34 wk $(\times 6,250)$. M, mesangium; B, Bowman's space; $C$, capillary lumen. There is marked mesangial expansion owing to increased matrix and collagen. The capillary basement membrane is thickened. Epithelial cell foot processes are obliterated

UNX SHR, at 10 wk of age, only 5 wk after nephrectomy. At that age, SHR have significant hypertension (14) and the increase in RPF and GFR after nephrectomy are already complete (4); however, proteinuria and histologic evidence of renal disease are not yet apparent (data not shown). We found that, compared with WKY rats, UNX in young SHR caused a significant reduction in afferent arteriolar resistance and an increase in $\overline{\mathrm{P}}_{\mathrm{GC}}$. Furthermore, it was this increase in glomerular pressure at 10 wk of age that predicted the appearance of proteinuria and morphologic abnormalities 4 mo later.

The explanation for the conflicting finding of a normal value for $\bar{P}_{\mathrm{GC}}$ in the study of Bank et al. (15), and an increased value in the present study is uncertain. One possibility is that the lower value observed in the previous study was the result of extensive morphologic changes that are evident in the kidneys UNX SHR at $6 \mathrm{mo}$, but not at $10 \mathrm{wk}$ of age. However, this seems unlikely, for if the appearance of morphologic lesions caused glomerular pressure to decline, then the process should be self-correcting and not cause progressive renal injury. Alternatively, differences in superficial glomerular perfusion may have resulted from differences in the volume status of rats prepared for micropuncture study. In the present study, rats were made euvolemic by infusion of a volume of plasma that has been demonstrated (16) to maintain extracellular fluid volume relatively stable. Bank et al. (15)

and endothelial cell cytoplasm is swollen and shows reduced fenestrae. Insets: (a) a glomerular capillary wall from this rat compared to that (b) from a UNX WKY rat (group 2$)(\times 19,500)$. These capillary wall changes were noted only in glomeruli with marked mesangial expansion and in sclerosing glomeruli.

infused a mixed Ringer's, albumin solution which may not have fully compensated for the volume losses that result from anesthesia and surgery. Consistent with this hypothesis, it should be noted that the values for GFR and SNGFR reported by Bank et al. (15) are considerably lower than those reported from this and other $(17,18)$ laboratories, lower, in fact, than values reported for similarly sized rats studied under hydropenic conditions, without any volume replacement (19).

In contrast to their negative findings in superficial nephrons, Bank et al. (15) reported that filtration rate was dramatically increased in deep, juxtamedullary nephrons. This observation is further confirmed by the simple calculation of dividing whole kidney GFR by superficial SNGFR as an estimate of nephron number. In the aforementioned study, the calculated nephron number increased from 21,509 in intact SHR to 34,553 in UNX SHR. As the number of glomeruli does not actually increase in rats nephrectomized at this age, this apparent increase must have resulted from the fact that juxtamedullary SNGFR increased proportionally more than superficial SNGFR in UNX SHR. In the present study the juxtamedullary nephron filtration rate was not directly measured. However, the calculated nephron number remained essentially constant in intact and UNX SHR, averaging 26,555 and 24,121 , respectively. This suggests that in our rats, superficial and juxtamedullary nephron filtration rates increased 
similarly after UNX. Because it has been suggested that, during volume depletion, plasma flow and filtration rate are reduced in superficial cortical glomeruli but well maintained in juxtamedullary glomeruli, the relative hydropenia of the rats studied by Bank et al. (15) may again account for the different results in these two studies.

At 10 wk of age, GFR and SNGFR were lower in UNX SHR than in UNX WKY rats despite the fact that $\overline{\mathrm{AP}}$ was significantly greater in SHR. This was, in part, the result of a somewhat lower mean value for $Q_{A}$ in group 7, but in addition, calculated values for $K_{\mathrm{f}}$ were lower, on average, in the hypertensive rats. The mechanism of this reduction in $K_{\mathrm{f}}$ is uncertain. As $K_{\mathrm{f}}$ is equal to the product of the hydraulic conductivity of the glomerular capillary wall $(k)$, and the total capillary surface area available for filtration $(S)$, declines in the value of $K_{\mathrm{f}}$ can be brought about by reductions in $k$ or $S$. In the present study, alterations in $k$ or $S$ may have resulted from damage to the glomerular capillary wall in group 7; however, the histologic techniques that we employed revealed no such injury in UNX SHR at 10 wk of age, the time of micropuncture study. Alternatively, $K_{\mathbf{f}}$ might have been reduced because of functional declines in the value of $S$. Studies both in vivo (20) and in vitro (21) suggest that many vasoactive hormones reduce glomerular capillary surface area by promoting mesangial cell contraction. Evidence exists for increased sympathetic activity (22), elevated levels of renin (23), and increased glomerular synthesis of thromboxane $A_{2}$ and prostaglandins $I_{2}, E_{2}$, and $F_{2}$ in vitro (24) in SHR. Therefore, the low $K_{\mathrm{f}}$ we observed in young SHR may have resulted from hormonally mediated mesangial cell contraction tending to reduce glomerular capillary surface area in vivo.

In the present study, increased glomerular capillary pressure and flow preceded and predicted the development of proteinuria and morphologic evidence of glomerular injury in UNX SHR. To test further whether these changes in glomerular hemodynamics might have been responsible for the observed glomerular injury, we examined the effects of a low protein diet on structure and function in UNX SHR. This maneuver has been shown to influence intrarenal hemodynamics markedly and to blunt the increase in glomerular capillary perfusion that develops after extensive ablation of renal tissue (3), in mineralocorticoid-induced hypertension (2), or as a consequence of normal maturation (25).

Protein restriction had no effect on systemic blood pressure in UNX SHR, but caused glomerular capillary plasma flow and hydraulic pressure to decline to values similar to those observed in intact animals. Quantitative morphologic studies performed in SHR $31 \mathrm{wk}$ after UNX indicated that feeding the 6\% protein diet significantly decreased the level of proteinuria and incidence of glomerular abnormalities in these rats. Increased damage to the intrarenal vasculature was evident; however, this damage is unlikely to have contributed directly to the reduction in glomerular capillary pressure that we observed in protein-restricted rats in that glomerular pressure was already reduced at $10 \mathrm{wk}$, at which time no vessel abnormalities were present (data not shown). Therefore, in SHR, a maneuver that blunted the hemodynamic consequences of uninephrectomy also prevented structural glomerular injury and significant proteinuria. These findings are consistent with the hypothesis that sustained increases in glomerular capillary pressure and flow were themselves responsible for glomerular injury in UNX SHR.

Varying protein intake has previously been shown to affect dramatically the progression of several other forms of experimental renal disease. For example, feeding a high protein diet accelerated the rate of glomerular sclerosis in uninephrectomized rats $(26,27)$. Conversely, reducing dietary protein content prolonged survival $(28,29)$ and reduced glomerular injury $(30)$ of rats after ablation of renal tissue. Reducing dietary protein content has also been shown to lessen renal damage in nephrotoxic serum nephritis $(31,32)$ and diabetic nephropathy (33) in rats, and in the lupuslike nephropathy of the New Zealand Black/ New Zealand White mouse (34). In humans, studies in both advanced (35) and early renal failure (36) suggest that moderate protein restriction may retard the rate of deterioration of renal function in patients with a variety of renal diseases.

Micropuncture studies of glomerular dynamics in rats 1 wk after $90 \%$ ablation of renal mass (3) and in rats with DOC-SALT hypertension (2) confirm that, as in the present study, an important effect of protein restriction is to maintain glomerular hemodynamics at near normal levels. This suggests that the protective effect of dietary protein reduction resides in its ability to prevent increases in glomerular capillary pressure and flow. Alternatively, Karlinsky and co-workers (37) have suggested that phorphorus restriction may also protect rats with renal injury from developing progressive renal insufficiency. However, it is unlikely that differences in phosphorus intake or balance accounted for the beneficial effect of protein restriction in our study, inasmuch as dietary phosphorus content was similar in the $24 \%$ and $6 \%$ protein diets that we employed. Furthermore, rats ingesting the low protein diet excreted at least as much phosphate in $24 \mathrm{~h}$ as rats ingesting standard laboratory diet.

The mechanism whereby increased glomerular capillary perfusion produces glomerular damage is not known. Based primarily upon studies in the remnant kidney model, it has been proposed that a central event in the generation of glomerular injury is an increase in the ultrafiltration rate of water. This increased movement of filtrate across the glomerular capillary wall, so-called hyperfiltration, is associated with an increase in the transglomerular flux of macromolecules (38) including plasma proteins, a phenomenon that has been associated with glomerular sclerosis in other forms of experimental renal disease $(39,40)$. However, it seems unlikely that, in the present study, an increase in the single nephron or whole kidney glomerular filtration rate was the most important determinant of glomerular injury. At 10 wk of age, SNGFR and GFR were lower in hypertensive rats in group 7, which were destined to develop renal injury, than in normotensive rats in group 6. Because these lower filtration rates are predicted to be associated with parallel reductions in absolute protein filtration, it also seems unlikely that increased protein traffic through the glomerular mesangium is required for the initiation of glomerular injury in this model. Once damaged by some other mechanism, changes in the permeability of the glomerular capillary wall might result in augmented macromolecule filtration as a secondary event tending to perpetuate and exacerbate glomerular injury.

Support for the hypothesis that some factor other than a change in the filtration rate of water is responsible for hemodynamically mediated glomerular injury is also provided by our previous studies (2) in the DOC-SALT model of hypertension. In that model, histologic injury and proteinuria occurred exclusively in hypertensive DOC-SALT rats, despite the fact that uninephrectomized, normotensive control animals had similar increases in both plasma flow and filtration rates. Thus, hemo- 
dynamically mediated glomerular injury may occur in settings where measurements of plasma flow and filtration rate fail to clearly identify the population at risk. By analogy, it is possible that hemodynamic mechanisms may contribute to glomerular injury in a variety of other clinical and experimental forms of renal disease where measurements of whole kidney function are apparently normal.

In both the UNX SHR and DOC-SALT models of hypertension, it is the increase in glomerular capillary pressure rather than filtration rate that correlates most closely with the occurrence of glomerular injury. In DOC-SALT rats (2), this increase was associated with a large increase in $\mathrm{Q}_{A}$, suggesting a contribution of augmented glomerular plasma flow to glomerular injury. In the present study, however, values for $Q_{A}$ were significantly lower in SHR than in WKY rats that failed to develop significant glomerular damage. This indicates that large increases in $\mathrm{Q}_{\mathrm{A}}$ are not required for glomerular injury to occur, and that glomerular capillary hypertension is the most important determinant of hemodynamically mediated renal disease. That increased glomerular capillary pressure might cause glomerular injury in hypertension was first suggested by Azar et al. (1) based upon micropuncture studies of glomerular function in UNX Holtzman rats. Further support for this hypothesis has recently been provided by Anderson et al. (41), who reported that reducing glomerular capillary pressure without altering plasma flow or filtration rate retarded the progression of glomerular injury in rats after $85 \%$ renal ablation. We have shown (42) that glomerular damage is virtually unmodified by antihypertensive therapy that fails to prevent glomerular hypertension in rats with DOC-SALT hypertension. Increases in $\overline{\Delta \mathrm{P}}$ may injure the capillary network by a mechanism analogous to the effects of hypertension on systemic arterial vessels, possibly involving mechanical disruption of normal vascular integrity (43). Accordingly, in protein-restricted SHR, persistent systemic hypertension was associated with significant morphologic arterial and arteriolar damage, whereas normalization of glomerular capillary pressure protected the glomerular capillary from injury.

Based upon these observations it is likely that, in patients or animals with elevated blood pressure, glomerular damage will occur only if increased hydraulic pressure is transmitted to the glomerular capillary. Regardless of the level of the systemic blood pressure, glomerular capillary pressure is determined by the levels of the afferent and efferent arteriolar resistances. Afferent arteriolar resistance is relatively high in superficial nephrons of intact SHR when compared with WKY rats, so that $\bar{P}_{G C}$ is not elevated (17-19) and these glomeruli are protected from hypertensive injury. Uninephrectomy decreases $\mathbf{R}_{A}$, glomerular capillary pressure increases, and glomerular damage ensues. Further evidence for the central role of the afferent arteriole was provided by Raij et al. (44), who suggested that the combination of systemic hypertension and afferent arteriolar vasodilation may exacerbate ferritin-antiferritin immune complex glomerulonephritis. In two similar studies, Tikkanen et al. (45) examined the effects of DOC-SALT hypertension on the course of autologous immune complex nephritis (Heymann nephritis), and Neugarten and co-workers (46) the effects of superimposed twokidney, one-clip Goldblatt hypertension on the course of nephrotoxic serum nephritis in rats. In both studies, rats with hypertension and nephritis demonstrated increased proteinuria and more severe renal histologic lesions than nephritic rats with normal blood pressures. Because reduced afferent arteriolar resis- tance is characteristic of both these models, it is attractive to speculate that augmented glomerular capillary hydraulic pressure enhanced the immune-mediated glomerular injury in these animals.

Employing the preceding hypothesis, it is possible to predict the clinical situations in which systemic arterial hypertension will be associated with progressive glomerular sclerosis. For example, afferent arteriolar tone and resistance are reduced early in the natural history of diabetes mellitus and measurements of renal function reveal increased RPF and GFR (47). Importantly, these alterations in glomerular perfusion predict the eventual occurrence of diabetic nephropathy (48). In many patients with mild-to-moderate renal insufficiency, damage to the kidney may be heterogeneous, so that some nephrons undergo atrophy and others hypertrophy (49). These enlarged glomeruli increase their function by virtue of a decrease in afferent resistance, leading to an increase in flow and pressure within the capillary network. These hyperfunctioning nephrons are at increased risk for hypertensive injury should blood pressure become elevated. By analogy with animal studies, patients who have lost a kidney to trauma, surgery, or as a consequence of kidney donation are also predicted to have reduced values for $\mathbf{R}_{A}$ compared to normal adults. One may predict that such individuals are also at increased risk for the development of hypertensive nephrosclerosis.

A few clinical studies support the preceding prediction. In patients with chronic renal insufficiency, it has been suggested that uncontrolled systemic hypertension may hasten the progression to uremia (50). It has also been suggested that therapy with antihypertensive agents may retard the rate of functional decline in some patients with mild-to-moderate renal dysfunction (51), or with diabetes mellitus, nephropathy, and hypertension $(52,53)$. Finally, increased urinary protein excretion has been documented in kidney donors studied more than $10 \mathrm{yr}$ after nephrectomy (54). The finding in the present study provides an attractive explanation for these clinical observations and a rationale for the aggressive control of blood pressure in all hypertensive patients with renal functional abnormalities.

In summary, SHR uninephrectomized at 5 wk of age have significant elevation of the glomerular transcapillary hydraulic pressure gradient by $10 \mathrm{wk}$ of age as compared to normotensive UNX WKY rats. These hypertensive rats go on to develop structural abnormalities of their glomeruli and increased urinary protein excretion. Reducing dietary protein intake prevents the increment in glomerular capillary pressure and protects UNX SHR from proteinuria and morphologic evidence of glomerular disease. This protective effect of protein restriction is not explained by differences in phosphate intake or balance. These findings suggest that glomerular capillary hypertension predisposes to glomerular injury in this model of systemic arterial hypertension and further support the hypothesis that increased glomerular capillary pressure causes progressive glomerular sclerosis in a wide variety of renal diseases.

\section{Acknowledgment}

During these studies Dr. Dworkin was the recipient of New Investigator Award HL-30889 from the National Institutes of Health.

\section{References}

1. Azar, S., M. A. Johnson, B. Hartel, and L. Tobian. 1977. Single nephron pressures, flows and resistances in hypertensive kidneys with nephrosclerosis. Kidney Int. 12:28-40. 
2. Dworkin, L. D., T. H. Hostetter, H. G. Rennke, and B. M. Brenner. 1984. Hemodynamic basis for glomerular injury in rats with desoxycoritcosterone-salt hypertension. J. Clin. Invest. 73:1448-1461.

3. Hostetter, T. H., J. L. Olson, H. G. Rennke, M. A. Venkatachalam, and B. M. Brenner. 1981. Hyperfiltration in remnent nephrons: a potentially adverse response to renal ablation. Am. J. Physiol. 241:F85F93.

4. Deen, W. M., D. A. Maddox, C. R. Robertson, and B. M. Brenner. 1974. Dynamics of glomerular ultrafiltration in the rat. VII. Response to reduced renal mass. Am. J. Physiol. 227:556-562.

5. Steffes, M. W., D. M. Brown, and S. M. Mauer. 1978. Diabetic glomerulopathy following unilateral nephrectomy in the rat. Diabetes. 27:35-41.

6. Wachtel, L. N., L. J. Cole, and V. J. Rosen. 1966. X-ray glomerulosclerosis in rats: modification of lesion by food restriction, uninephrectomy, and age. J. Gerontol. 21:442-448.

7. Glasser, R. J., J. A. Velosa, and A. F. Michael. 1977. Experimental models of focal sclerosis. I. Relationship to protein excretion in aminonucleoside nephrosis. Lab. Invest. 36:519-526.

8. Fuhr, J., J. Kaczmarczyk, and C. D. Kruttgen. 1955. Eine einfache colorimetrische Methode zur Inulinbestimmung fur Nierenclearanceuntersuchungen bei Stoffwechselgesunden und Diabetikern. Klin. Wochenschr. 33:729-730.

9. Frankel, S., S. Reitman, and A. C. Sonnenwirth. 1970. Gradwohl's Clinical Laboratory Methods and Diagnosis. 7th ed. C. V. Mosby Co., St. Louis. 185

10. Baylis, C., W. M. Deen, B. D. Myers, and B. M. Brenner. 1976. Effects of some vasodilator drugs on transcapillary fluid exchange in renal cortex. Am. J. Physiol. 230:1148-1158.

11. Viets, J. W., W. M. Deen, J. L. Troy, and B. M. Brenner. 1978. Determination of serum protein concentration in nanoliter blood samples using florescamine or O-phthalaldehyde. Anal. Biochem. 88:513-521.

12. Allison, M. E. M., E. M. Lipham, and C. W. Gottschalk. 1972. Hydrostatic pressure in the rat kidney. Am. J. Physiol. 223:975-983.

13. Wallenstein, S., C. L. Zucker, and J. L. Fleiss. 1980. Some statistical methods useful in circulation research. Circ. Res. 47:1-9.

14. Feld, L. G., J. B. Van Liew, R. G. Galeske, and J. W. Boyland. 1977. Selectivity of renal injury and proteinuria in the spontaneously hypertensive rat. Kidney Int. 12:332-343.

15. Bank, N., L. Alterman, and H. S. Aynedjian. 1983. Selective deep nephron hyperfiltration in uninephrectomized spontaneously hypertensive rats. Kidney Int. 24:185-191.

16. Ichikawa, I., D. A. Maddox, M. G. Cogan, and B. M. Brenner. 1978. Dynamics of glomerular ultrafiltration in euvolemic MunichWistar rats. Renal Physiol. 1:121-131.

17. Arendshorst, W. J., and W. H. Beierwaltes. 1979. Renal and nephron hemodynamics in spontaneously hypertensive rats. Am. J. Physiol. 236:F246-F251.

18. Azar, S., M. A. Johnson, J. Scheinman, L. Bruno, and L. Tobian. 1979. Regulation of glomerular capillary pressure and filtration rate in young Kyoto hypertensive rats. Clin. Sci. (Oxf.) 56:203-209.

19. DiBona, G. F., and L. L. Rios. 1978. Mechanism of exaggerated diuresis in spontaneously hypertensive rats. Am. J. Physiol. 235:F409F416.

20. Schor, M., I. Ichikawa, and B. M. Brenner. 1981. Mechanisms of action of various hormones and vasoactive substances on glomerular ultrafiltration in the rat. Kidney Int. 20:442-451.

21. Ausiello, D. A., J. J. Kriesberg, C. Roy, and M. J. Karnovsky. 1980. Contraction of cultured rat glomerular mesangial cells after stimulation with angiotensin II and arginine vasopressin. J. Clin. Invest. 65: 754-760.

22. Landsberg, L., and J. B. Young. 1981. Sympathetic nervous system in hypertension. In Hypertension. B. M. Brenner and J. H. Stein, editors. Churchill Livingstone, Inc., New York. 100-141.

23. Vincent, M., J. Dupont, and J. Sassard. 1976. Plasma renin activity as a function of age in two new strains of spontaneously hypertensive and normotensive rats. Clin. Sci. Mol. Med. 50:103-107.
24. Konieczkowski, M., M. J. Dunn, and A. Hassid. 1982. Glomerular synthesis of prostaglandins and thromboxanes in spontaneously hypertensive rats. Fed. Proc. 41:1593.

25. Ichikawa, I., M. L. Purkerson, S. Klahr, J. L. Troy, M. MartinezMaldonado, and B. M. Brenner. 1980. Mechanism or reduced glomerular filtration rate in chronic malnutrition. J. Clin. Invest. 65:982-988.

26. Blatherwick, N. R., and E. M. Medlar. 1937. Chronic nephritis in rats fed high protein diets. Arch. Intern. Med. 59:572-596.

27. Lalich, J. L., P. M. Burkholder, and W. C. W. Paik. 1975. Protein overload nephropathy in rats with unilateral nephrectomy. Arch. Pathol. 99:72-79.

28. Kleinknecht, C., I. Salusky, M. Broyer, and M. C. Gubler. 1979. Effect of various protein diets on growth, renal function, and survival of uremic rats. Kidney Int. 15:534-541.

29. Salusky, I., C. Kleinknecht, M. Broyer, and M. C. Gubler. 1981. Prolonged renal survival and stunting, with protein deficient diets in experimental uremia: reversal of these effects by addition of essential amino acids. J. Lab. Clin. Med. 97:21-000.

30. Meyer, T. W., T. H. Hostetter, H. G. Rennke, J. L. Noddin, and B. M. Brenner. 1882. Preservation of renal structure and function by long term protein restriction in rats with reduced nephron mass. Am. Soc. Nephrol. 15:125A. (Abstr.)

31. Farr, L. E., and J. E. Smadel. 1939. The effect of dietary protein restriction on the course of nephrotoxic serum nephritis in rats. J. Exp. Med. 70:615-627.

32. Neugarten, J., H. Feiner, R. G. Schacht, and D. S. Baldwin. 1983. Amelioration of experimental glomerulonephritis by dietary protein restriction. 1983. Kidney Int. 24:595-601.

33. Liu, D., J. Neugarten, H. Feiner, R. G. Schact, and D. S. Baldwin. 1983. Influence of dietary protein content on the course of experimental diabetic nephropathy. Am. Soc. Nephrol. 16:111A. (Abstr.)

34. Friend, P. S., G. Fernandes, R. A. Good, A. F. Michael, and E. J. Yunis. 1978. Dietary restrictions early and late: effects on nephropathy in NZB X NZW mouse. Lab. Invest. 38:629-632.

35. Mitch, W. E., M. Walser, T. I. Steinman, S. Hill, S. Zeger, and K. Tungsanga. 1984. The effect of a keto acid-amino acid supplement to a restricted diet on the progression of chronic renal failure. N. Engl. J. Med. 311:626-629.

36. Maschio, G., L. Oldrizzi, N. Tessitore, A. D'Angelo, E. Valvo, A. Lupoa, C. Loschiavo, A. Fabris, L. Gannmaro, C. Rugiu, and G. Panzetta. 1982. Effects of dietary protein and phosphorous restriction on the progression of early renal failure. Kidney Int. 22:371-376.

37. Karlinsky, M. D., L. Haut, B. Buddington, N. A. Schrier, and A. C. Alfrey. 1980. Preservation of renal function in experimental glomerulonephritis. Kidney Int. 17:293-302.

38. Olson, J. L., T. H. Hostetter, H. G. Rennke, B. M. Brenner, and M. A. Venkatachalam. 1982. Altered glomerular permselectivity and progressive sclerosis following extensive ablation of renal mass. Kidney Int. 22:112-126.

39. Davies, D. J., D. B. Brewer, and J. Hardwicke. 1978. Urinary proteins and glomerular morphology in protein overload proteinuria. Lab. Invest. 38:232-243.

40. Glasser, R. J., J. A. Velosa, and A. F. Michaels. 1977. Experimental model of focal sclerosis. I. Relationship to protein excretion in aminonucleoside nephrosis. Lab. Invest. 36:519-526.

41. Anderson, S., T. W. Meyer, H. G. Rennke, and B. M. Brenner. 1985. Control of glomerular hypertension limits glomerular injury in rats with reduced renal mass. J. Clin. Invest. 76:612-619.

42. Dworkin, L. D., H. D. Feiner, and J. Randazzo. 1984. Evidence for hemodynamically mediated glomerular injury despite antihypertensive therapy in rats with desoxycorticosterone-salt hypertension. Am. Soc. Nephrol. 17:91A. (Abstr.)

43. Parving, H. H., and F. Gyntelburg. 1973. Transcapillary escape rate of albumin and plasma volume in essential hypertension. Circ. Res. 32:643-651.

44. Raij, L., S. Azar, and W. F. Keane. 1982. Role of hypertension 
and mesangial injury in progressive glomerular damage. $\mathrm{Am}$. Soc. $\mathrm{Ne}$ phrol. 15:126A. (Abstr.)

45. Tikkanen, I., F. Fyrquist, A. Miettinen, and T. Tornroth. 1980. Autologous immune complex nephritis and DOCA- $\mathrm{NaCl}$ load: a new model of hypertension. Acta Pathol. Microbiol. Scand. Sect. A Pathol. 88:241-250.

46. Neugarten, J., H. D. Feiner, R. G. Schacht, G. R. Gallo, and D. S. Baldwin. 1982. Aggravation of experimental glomerulonephritis by superimposed clip hypertension. Kidney Int. 22:257-263.

47. Mogensen, C. E. 1971. Glomerular filtration rate and renal plasma flow in short-term and long-term juvenile diabetes mellitus. Scand. $J$. Clin. Lab. Invest. 29:91-100.

48. Mogensen, C. E., and C. K. Christensen. 1984. Predicting diabetic nephropathy in insulin dependent patients. N. Engl. J. Med. 311:89-93.

49. Oliver, J. 1939. Architecture of the Kidney in Chronic Bright's Disease. Paul B. Hoeber, New York.
50. Moyer, J. H., C. Heider, K. Pevey, and R. V. Ford. 1958. The effect of treatment on the vascular deterioration associated with hypertension with particular emphasis on renal function. Am. J. Med. 24:177192.

51. Mitchell, H. C., R. M. Graham, and W. A. Pettinger. 1980. Renal function during long-term treatment of hypertension with minoxidil. Ann. Intern. Med. 93:676-681.

52. Mogensen, C. E. 1982. Long-term antihypertensive treatment inhibiting progression of diabetic nephropathy. Br. Med. J. 285:685688.

53. Parving, H. H., A. R. Andersen, U. M. Smidt, and P. A. A. Svendsen. 1983. Early aggressive antihypertensive therapy reduces rate of decline in kidney function in diabetic nephropathy. Lancet. $i: 1179$ 1183.

54. Hakim, R. M., R. C. Goldszer, and B. M. Brenner. 1984. Hypertension and proteinuria: long-term sequelae of uninephrectomy in humans. Kidney Int. 25:930-936. 